\title{
The Influence of Taoism and Taoism on Tea-chanting Poems in Tang Dynasty
}

\author{
Li Yang, ${ }^{1,}$, Kong Linghong ${ }^{2}$ \\ ${ }^{1}$ Cultural Communication and Design, Dongfang College of Zhejiang University of Finance and Economics, Haining, China \\ ${ }^{2}$ Department of Philosophy, Zhejiang University, Hangzhou, China
}

\section{Email address:}

dd00571@qq.com (Li Yang),kz76s@126.com (Kong Linghong)

${ }^{*}$ Corresponding author

\section{To cite this article:}

Li Yang, Kong Linghong. The Influence of Taoism and Taoism on Tea-chanting Poems in Tang Dynasty. Asia-Pacific Journal of Humanities and Social Sciences. Vol. 8, No. 2, 2019, pp. 32-37. doi: 10.11648/j.si.20200802.13

Received: September 23, 2019; Accepted: November 5, 2019; Published: May 19, 2020

\begin{abstract}
Taoists are pleasure to drinking tea while practicing alchemy. Taoism had a very high cultural status in Tang Dynasty. The use and importance of tea by Taoist priests inevitably make broader impacts in the whole society. In fact, Taoism had a wide and profound influence on the tea-chanting poetry in Tang Dynasty. This paper takes Lu Yu, Jiaoran, Lu Tong and others as examples to illustrate, and give consideration to the general aspects. The reason for this is that, firstly, the highest rulers of the Tang Dynasty unprecedentedly placed Taoism at the top of Confucianism, and Buddhism, which had a wide and far-reaching impact in the field of culture. Literatis are eager to understand Taoism and believe in Taoism has become a fashion. This must be reflected in tea culture. Secondly, literatis regard drinking tea as an activity to regulate mood and highlight oneself, and gradually enhance tea cultural, so "tasting" tea has become an art, that is, tea ceremony.
\end{abstract}

Keywords: Tang Dynasty, Taoism, Tea Poetry

\section{道家、道教与唐代咏茶诗 ${ }^{1}$}

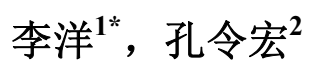

${ }^{1}$ 浙江财经大学东方学院文化传播与设计分院, 海宁, 中国

2浙江大学哲学系, 杭州, 中国

\section{邮箱}

dd00571@qq.com（李洋），kz76s@126.com（孔令宏）

摘要：道教徒在炼服丹药的同时，也一直重视饮茶。道教在唐代具有很高的文化地位，道士对茶的运用和重视，必然 对教外人士的茶饮产生影响。事实上, 道家、道教对唐代咏茶诗产生了广泛而深刻的影响, 本文以陆羽、皎然、卢全等 人为典型例子作了分析, 又兼顾一般作了面上的阐述。之所以如此, 原因在于, 其一, 唐代最高统治者史无前例地把 道教位列儒、佛、道三家之首, 这在文化领域产生了广泛而深远的影响。文人士大夫对道教趋之若烝, 理解道家思想, 信仰道教成为时尚。这必然在茶文化中体现出来。其二, 文人士大夫视饮茶为调节心情、彰显自我的活动, 逐渐提升 茶事的文化品位, “品”茶成了一种艺术, 即茶道。

关键词: 唐代, 道家, 道教, 咏茶诗 


\section{1. 引言}

在茶文化的研究中, 学者们对佛教与茶的关系关注很 多, 论著很多。相比之下, 忽视了道家、道教与茶的关系, 这方面的论文不多, 著作尚未见到。本文力图在既有研究 的基础上有所深化。

汉代以来, 道家、道家与茶的关系日趋紧密, 唐代尤 其如此。道教徒在进行各种服务于成仙得道的活动的同时, 也喜欢饮茶。唐代许浑的诗《送张炼师归洞庭》说:“能琴 道士洞庭西......杉松近晚移茶灶, 岩谷初寒盖药畴。”““移 茶灶”表明道士把抚琴、喝茶、用药看得同等重要。韩翃 的《寻胡处士不遇》诗说道:“微风吹药案, 晴日照茶巾”。 “茶巾”与“药案”对举, 强调了道士对养生的追求。周贺的 诗《玉芝观王道士》描述了玉芝观“曲角积茶烟”, 说明道 观饮茶已经有悠久的历史, 否则不会留下明显的茶烟痕迹。 著名女道士鱼玄机《访赵炼师不遇》中有“暖炉留者药, 邻院为煎茶”之句, 说明煮药、煎茶是道士们日常生活中 的普遍性行为。唐代诗人温庭筠作《西陵道士茶歌》, 说: “乳窦㳚浅通石脉, 绿尘愁草春江色。洞花入林水味香, 山月当人松影直。仙翁白扇霜乌翎, 拂坛夜读《黄庭经》。 疏香皓齿有余味, 更觉鹤心通杳冥。”在山清水秀、寂静 安宁的夜晚, 道士边饮茶边诵读《黄庭经》。饮茶让人清 虚宁静, 道经也以守静致虚为宗旨, 二者交相辉映, 人心 因此飘渺于俗世之外, 查冥之中。李约（751-810? ）, 陇西成纪 (今甘肃天水县) 人, 字存博, 宗室宰相李勉之 子, 小郑王房李元懿之后。注《老子道德经》四卷, 被称 作《老子道德新经》, 也称李注《道德经》或《老子新注》。 他工书善画, 长于作诗, 嗜茶。《因话录》记载, “能自 煎。曾奉使行硖石县东, 爱渠水清流, 旬日忘发。客至, 不限瓯数, 竟日执持茶器不倦。谈其艺, 说: “茶须缓火 炎, 活火煎。活火谓炭火焰火也。”他所提出的“活火”说, 在后世茶道中颇有影响。

\section{2. 李洋, 孔令宏, 道家、道教对唐代咏茶诗的 影响}

\section{1. 唐代咏茶诗道韵三例}

道教在唐代地位很高, 道士对茶的运用和重视, 必然 对教外人士的茶饮产生影响。唐代道家、道教对茶饮的影 响, 我们举三个例子。其一为隐士文人陆羽, 其二为半道 半僧的賋然, 其三为半道半儒的卢全。

陆羽（733-804年），自号竟陵子、桑草翁、东冈子、 茶山御史。编著《谑谈》和《茶经》各三卷。此前学者们 多谈佛教对陆羽的影响, 我们认为, 道家、道教对陆羽的 影响也不可忽视，表现在六方面:

2 [清]彭定求等编, 《全唐诗》, 郑州: 中原出版传媒集团2018年版, 第 5 卷, 第 2754 页。

3 [清]彭定求等编, 《全唐诗》, 郑州: 中原出版传媒集团2018年版, 第244卷第1250页。

4 [唐]赵璘: 《因话录・乾巽子》, 北京: 中华书局1985年版, 第11页。
其一, 《茶经》是茶学诞生的标志。但《茶经》是以 道家思想为其哲学基础的。《茶经・一之源》说: “茶之 为用, 味至寒, 为饮最宜精行俭德之人。”这是《道德 经》崇简抑奢思想的反映!《茶经》所讲的“精”、“俭”、“静”、 “德”等茶饮之道, 是道家、道教思想的典型运用。

其二, 陆羽的诗作中多有道教思想的运用。例如, 在 江西洪州玉芝道观，他写诗表明心迹: “不羡黄金垒, 不 羡白玉杯, 不羡朝入省, 不羡暮登台, 千羡万羡西江水, 曾向竟陵城下来” 6 。如此清心道远的诗言, 可谓其不求名 不逐利, 只求精神自由的心境写照。

其三, 陆羽终身隐居不仕, 有隐士之风。他 49 岁时, 朝廷封他为太常寺太祝(祭祀官), 他坚决不就, 淡泊名利, 不为名累, 奔波于大山河流, 精于茶事, 孜孜不倦于茶业。 隐士之风, 向为道家、道教所赞誉。陆羽的号竟陵子、桑 草翁、东冈子等，充满了道家和隐士之风。

其四, 《茶经》认为, 神农氏是最早使用茶叶的人, 而神农氏是道教崇敬奉的祖先神和农业神。《茶经》提及 历代多位道教学者撰写的著述。《茶经》所列饮茶之人, 大部分为道家、道教人物。《茶经》还多次引用羽化成仙 的典故, 意在让人把饮茶与修炼成仙关联在一起。

其五，道教其实是道家思想的继承者和实践者。陆羽 所设计的茶炉, 是在易经八卦和阴阳五行学说的指导下完 成的。茶炉用铜、铁制作，为三足之鼎。一足铸“坎上巽 下离于中”, 说的是茶炉的结构。煮茶时, 水 (坎) 置于上 面, 风 (巽) 从下面吹入, 火 (离) 在中间燃烧。一足铸“体 均五行去百疾”, 描述的是饮茶的功效: 能使五脏调和, 百病不生。在炉口上方, 设三个用于支撑茶全复的支垛, 每个支垛分别铸上“巽”、“离”、“坎”符号以及象征风兽的 “彪”、象征火禽的“翟”和象征水虫的“鱼”, 其涵义与足上 所铸文字一致。茶炉壁体“厚三分, 缘阔九分, 令六分虚 中”。“三”、“六”、“九”是象数易学中经常用到的数字。总 体看来, 陆羽设计的茶炉在象数易学的指导下进行的。易 学从西汉以来分化为义理与象数两派, 义理派追随儒学发 展, 象数派依附道教而绵延。此外, 茶炉上刻“伊公美、 陆氏茶”。伊公是远古的仙人, 不食烟火只以杽食。炉身 上还刻出“曲水”和道教三岛之一方丈。十洲三岛是上古仙 境。这说明, 陆羽的茶炉极有可能是模仿烧炼外丹的炉鼎 而设计的。

其六, 路羽被后世茶业从业者奉为茶神。就在唐代, 民间已把陆羽奉为茶业保护神。《新唐书・陆羽传》：“羽 嗜茶，著经三篇。时譬茶者，至陶羽形，置炀突间，祀为 茶神”。7 《因話錄》也说: “今韾茶之家, 陶其像置锡器之 间，云：宜茶足利，今为鸿渐（即陆羽）形者，因目为茶 神，有交易则茶祭之，无则釜汤沃之。”河北唐县出土了 一尊白瓷陆羽像, 陆羽头戴道士荷花冠, 双腿跃谷窝, 面

5 [唐]陆羽著, 王麓一编, 《茶经》, 北京: 中国纺织出版社 2018 年版, 第24页

6 [清]彭定求等编, 《全唐诗》, 郑州: 中原出版传媒集团2018年版, 第308卷, 第1579页。

7 《新唐书·陆羽传》, 北京: 中华书局 2000 年版, 第3卷, 第5609页。 8 [唐] 赵璘, 《欽定四庫全書子部1062》, 杭州: 杭州出版社2015版, 第518頁 
部如童稚小儿。“肌肤若冰雪, 绰约若处子”, 这是《庄子》 中对神仙的描述。直到近现代, 一些茶铺的炉灶上仍供陆 羽神像。把有功于民或某方面能力超强者奉为神, 这是道 教的传统做法。

《茶经》作为第一部茶学著作, 在后世影响深远。陆 羽因此被后世尊称为“茶圣”, 被茶业从业者视为行业保护 神而称为“茶神”。由于陆羽深受道家、道教的影响, 后世 也称他为“茶仙”。元代辛文房的《唐才子传·陆羽》则直接 说: “羽嗜茶, 造妙理, 著《茶经》三卷......时号“茶仙”。” 皎然（730-799），俗姓谢，字清昼，湖州（浙江吴 兴) 人, 是中国山水诗创始人谢灵运的十世孙, 唐代著名 诗人、茶僧, 吴兴杼山妙喜寺主持, 在文学、佛学、茶学 等方面颇有造诣。他与颜真卿、灵澈、陆羽等和诗, 现存 470 首诗, 多为送别酬答之作。他主张“以茶代酒”, 是以 茶为饮之风的积极推广者, 具体表现在倡导、策划、组织 了“品苔会”、“斗茶赛”、“诗茶会”, “顾渚茶赛”、“矨溪诗 茶会”就是其中的经典案例。由于他的僧人身份, 人们多 把他视为佛教茶的代表, 称其为“茶僧”。但是, 如果仔 细阅读他的诗作, 就会发现, 自交然的文风宗道家简约朴质 自然之道, 其诗虽云佛事, 实以道为本。陆羽是皎然的至 交。《寻陆鸿渐不遇》说:

移家虽带郭, 野径入桑麻。近种篱边菊, 秋来末著花。 扣门无犬吠, 欲去问西家。报道山中去, 归时每日斜。10 此诗为皎然访陆羽不遇之作。它用种养桑麻菊花、邀 游山林等很平常的事物描写了作者乘兴而来、兴尽而返的 旅程, 刻画了隐士闲适、清静的生活情趣。语言简洁、朴 素、平实, 不加雕饰, 流畅潇酒, 层次分明, 音调和谐。 这显然是张扬本真, 以朴素为美的道家精神的体现。

陆羽钟情于道家、道教, 作为好朋友的皎然也同样, 同样的精神追求大概是他们能成为至交的重要原因之一。 皎然的诗《饮茶歌送郑容》写道:

丹丘羽人轻玉食, 采茶饮之生羽翼。名藏仙府世莫知, 骨化云宫人不识。

云山童子调金铛, 楚人茶经虚得名。霜天半夜芳草折, 烂漫缃花啜又生。

常说此茶袿我疾, 使人胸中荡忧栗。日上香炉情未毕, 乱踏虎溪云, 高歌送君出。11

诗中满是丹丘、羽人、玉食、羽翼、仙府、云宫、云 山、金铛、香炉等仙家玄语。例如, 丹丘即羽人丘, 神话 传说中仙人居住地。诗人用夸张的手法, 从茶的祛疾、舒 心等养生功效推出仙人食茶羽化, 誉仙茶之珍奇, 既是发 明茶理, 也是张扬道教。如果没有对道教的深入了解和满 心欣赏, 绝难写出如此好诗。

如果说此诗对道教的理解还停留在用典之表象上, 那

么, 《饮茶歌诮崔石使君》则深入道家、道教之骨髓了:

越人遗我制溪茗, 采得金牙懸金鼎。

素瓷雪色缥沫香, 何似诸仙琼芯浆。

9 [元]辛文房: 《唐才子传》, 北京: 古典文学出版社1957年版, 第3 卷 第 50 页。

10 [清] 彭定求等编, 《全唐诗》, 郑州: 中原出版传媒集团2018年版, 第 815 卷, 第4111页。

11 [清]彭定求等编, 《全唐诗》, 郑州: 中原出版传媒集团2018年版, 第821卷, 第 4147 页。
一饮涤昏㝥, 情来朗爽满天地。 再饮清我神, 忽如飞雨酒轻尘。 三饮便得道，何须苦心破烦恼。 此物清高世莫知, 世人饮酒多自欺。 愁看毕卓瓮间夜, 笑向陶潜篱下时。 崔侯啜之意不已, 狂歌一曲惊人耳。 孰知茶道全尔真, 唯有丹丘得如此。12

“牙”通“芽”，即新采的黄绿色相间的茶芽，称之为金 芽, 当是受道士把炼丹时的铅华称为“黄芽”的影响。黄芽 具有让人长生不老的功效。诗中于是把精美白瓷中的美味 茶汤比喻为仙人饮用的玉液琼浆。接着, 诗中把品茶过程 分为三个步骤, 各有不同的功效。诗中用夸张的手法描写 了饮茶“涤昏奬”、“清神”、“得道”的三重功效。在他之前, 没有人把品茶过程中的文化内涵描述得这般细淢。这不是 饮茶, 而是品茶。这还不是普通的品茶, 更是悟道! 在这 个意义上, 诗中最后宣称, 只有神仙才懂得茶道之真谛! 此诗通篇陈述道教言辞意象, 识清明真, 与其说是深谙茶 意的诗, 不如说是一篇深谙道意的华章。晈然可谓饮茶的 精神价值的开发者。

在道文化的影响下, 皎然把品茶的最高境界称为“道”, 并在茶文化史上第一次提出了“茶道”的概念。由此, 饮茶 即是修道, 饮茶即可得道。皎然的思路是, 养生延寿是修 道的初级功夫，饮茶也具有“涤昏將”之功; 修身养性是修 道的中级功夫, 饮茶也有“清我神”的中级之效; 返朴归真 是修道的高级功夫，饮茶完全不同于“世人饮酒徒自欺”, 与修道一样也有返朴归真之效, 兵可再升华到“道”这一哲 理之本体、信仰之终极目标、精神境界的最高层次和价值 观的最高标准（“三饮便得道，何须苦心破烦恼”)。道家、 道教所谈的道, 是超越了自然界、世俗社会的种种束缚, 能够永恒存在, 获得绝对自由的“无待”、“自然”、“无为”。 在其指导下, 精神自由的向往和肉体长生的理想被凝聚到 得道成仙的终极信仰目标上, 进而为此在实践中作了多方 面的探索。

晈然此诗还有一大贡献。它把酒与茶相对照, 认为“诗 人饮酒多自欺”，而“清高”之茶“世莫知”，更不知其“全尔 真”的功效。也就是说, “真”是茶饮的最高审美境界!

作为美学、哲理概念, “真”最早显发于先秦著作《庄 子》。在茶文化发展过程中, 真的哲学、美学理蕴是逐渐 彰显的。张华《博物志》、刘馄《与兄子南衰州刺史演书》 中的“真茶”, 讲的都是单一、纯粹的意思, 即茶中不掺杂 物。这是对当时流行的“茶粥”的反拨。这种“真”的主张已 经含羞地包括了纯素、守真的意思, 只不过没有明说。皎 然的诗则把它们明明白白地说出来了! “孰知茶道全尔真, 唯有丹丘得如此。”把茶道的核心思想确定为“全尔真”。

“真”是道家文化的根本价值观, 即不假人为, 得自天成的 自然本性。这一概念, 得到了后世的认同与赞誉。例如, 宋人黄儒在《品茶要录》的序中说: “然士大夫间好珍藏精 试之具, 非尚雅好真, 未尝则出。”“好真”已经不是停留 于理论层次, 而是把崇尚自然的精神旨趣转化为一种爱好 了。在其影响下, 宋代苏轼在《和钱安道寄惠建茶》中写

12 [清]彭定求等编, 《全唐诗》, 郑州: 中原出版传媒集团2018年版, 第821卷, 第4146页。 
出了“吸过始知真味永”之句。“真味”显然不只是茶味, 还 是玄妙的自然之味, 更是道味!

从上可见, 皎然对道教文化的研究之深, 已非一般道 士可比。其《买药歌送杨山人》说:“河间姹女直千金，紫 阳夫人服不死。吾于此道复何如, 昨朝新得蓬莱书”。看 来, 他阅读了不少道教书籍。事实山, 皎然还写过作为纯 粹的道教诗歌体裁的《步虚词》。其《杂歌谣辞·步虚词》 说:

予因览真诀, 遂感西域君。玉笙下青冥, 人间未曾闻。

日华炼魂隗, 晈晈无垢氛。谓我有仙骨, 且令饵氮氲。

俯仰愧灵颜, 愿随鸾鹤群。俄然动风驭, 缥眇归青云。13

晈然确实是僧人, 所以, 我们无意夸大道教对他的影 响。他的《饮茶歌消崔石使君》中既有“三饮便得道, 何 须苦心破烦恼”的涉佛之论, 亦有“孰知茶道全尔真, 唯有 丹丘得如此”的道教之谈。“以儒治国, 以道养生, 以佛养 心”是古代统治者对儒、道、佛三教的态度, 其实质是三 教并用、三教融合。统治者如此, 普通老百姓更是如此。 一个人既信仰佛教, 也兼修道教, 这样的情况可谓比比皆 是。就茶文化而言, 僧人、道士的交游往来, 自唐代以来, 往往以茶作为媒介。佛教徒戒酒, 只能饮茶。道士们既可 以喝酒, 也可以饮茶, 茶于是成了日常生活中相互交流的 中介。佛教与道教都有超越的追求。日常生活表层的交流 是与内在精神的汇通相呼应的。《山谷外集詩注卷二》记 载, 南朝宋代, “新安王子莺、豫章王子尚访县济道人于 八公山, 道人设茶茗, 子尚味之曰: 此甘露也, 何言茶茗。”14 这极有可能是佛、道二教茶文化交流的最早记载。陆羽、 皎然等举办的抒山茶会, 出席的人物中遍及儒、道、释三 教。晈然的《饮茶歌送郑容》是因郑容采茶(“露天夜半芳 草折”赠他, “尝君此茶祛我疾”而作。郑容是“丹丘羽人” 一类, 那么, 这首诗描写的就是唐代僧、道之间茶文化的 交流活动。皎然还作有《奉应颜尚书真卿观玄真子置酒张 乐舞破阵画洞庭三山歌》, 同样描写了僧、道的雅集。唐 代僧人灵一有一首《妙乐观一一作题王乔观传傅道士所居》 诗, 写道士王乔邀其过访山观:

王乔所居空山观, 白云至今凝不散。坛场月路几千年, 往往吹笙下天半。

瀑布西行过石桥, 黄精采根还采苗。忽见一人檠茶碗, 答花昨夜风吹满。

自言家处在东坡，白犬相随邀我过。松间石上有棋局， 能使樵人烂斧柯。15

道士高高地擎举茶碗，邀请僧人，这是把茶作为友好 沟通的媒介, 表达僧、道之间的亲近、友善。齐已的《山 寺喜道者至》描写一个道土走访山寺, “茶好味重回”。品 茗之后, 余味缭绕, 久久不绝。更重要的是, 心神所触, 意蕴悠然。其他如温庭筜《宿一公精舍》的“茶炉天姥客” 等, 也是写僧、道边饮茶中边交流。所以, 茶文化的兴起 与发展, 既有佛教的贡献, 也有道家、道教的贡献。

13 [清]彭定求等编, 《全唐诗》, 郑州: 中原出版传媒集团2018年版, 第29卷, 第192页。

14 《文波阁四库全书集部五三别集类》, 载: 《文波阁四库全书》, 台北: 台湾商务印书馆1982年版，第1114-275页。

15 [清] 彭定求等编, 《全唐诗》, 郑州: 中原出版传媒集团 2018 年版, 第809卷, 第4090页。
唐代诗人卢全（约795-835）是个半道、半儒的悲剧 性人物。他早年隐居少室山, 后迁居洛阳。自号玉川子, 破屋中放满了图书, 埋首读书, 博览经史, 工于诗文, 靠 邻僧赠米度日, 不愿仕进。他的性格“高古介僻, 所见不 凡, ”狷介类孟郊, 雄豪之气近韩愈, 被视为韩孟诗派的 代表性人物。卢全诗风浪漫、奇论、险怪, 被称为“卢全 体”。835年11月夜宿宰相家, 不幸死于甘露之变。卢全好 茶成癖, 著有《茶谱》, 被尊称为“茶仙”。他的《走笔谢 孟谏议寄新茶》即《七碗茶歌》在历史上影响深远, 传唱 千年而不衰:

日高丈五睡正浓, 军将打门惊周公。

口云谏议送书信, 白绢斜封三道印。

开缄宛见谏议面, 手阅月团三百片。

闻道新年入山里, 蛰虫惊动春风起。

天子须尝阳羡茶, 百草不敢先开花。

仁风暗结珠蓓蕾, 先春抽出黄金芽。

摘鲜焙芳旋封裹, 至精至好且不奢。

至尊之余合王公, 何事便到山人家。

柴门反关无俗客, 纱帽笼头自煎吃。

碧云引风吹不断, 白花浮光凝碗面。

一碗喉吻润, 两碗破孤闪。

三碗搜枯肠, 唯有文字五千卷。

四碗发轻汗, 平生不平事, 尽向毛孔散。

五碗肌骨清, 六碗通仙灵。

七碗吃不得也, 唯觉两腋习习清风生。

蓬莱山, 在何处?

玉川子, 乘此清风欲归去。

山上群仙司下土, 地位清高隔风雨。

安得知白万亿苍生命, 惧在巅崖受辛苦。

便为谏议问苍生, 到头还得苏息否? ${ }^{16}$

本诗之吟, 最为脍多人口。“入山里”“到山人家”“柴门 反关无俗客”直指甘于清贫, “道与俗反”的道家隐士风范。 “纱帽笼头”意谓珍重洁净之茶, 自整衣冠, 自尊、自重、 自爱, 珍重生命。“七碗”茶水一一下肚, 人之感受的重心 也从物质转移到精神, 从“肌骨轻”、“通仙灵”到“两腋习习 清风生”, 飘飘如仙, 飞升太虚。这不只是描述饮茶的愉 悦和美感, 更是修炼成仙。饮茶的效果由此延伸出来的审 美感受, 在道文化的影响下被描写得绘声绘色。道教对茶 诗的影响, 在此诗中可谓表达得淋漓尽致。此诗因此与陆 羽《茶经》齐名, 他也因此被视为仙茶的代表, 与禅茶赵 洲相提并论。唐代杜牧在《春日茶山病不饮酒因呈宾客》 中称赞卢全对茶的研究之深, 说: “谁知病太守, 犹得作 茶仙”17。卢全此诗被后人累世赞誉不绝, 其词句被后代 茶诗大量摘引而用典。卢全被称为仅次于陆羽的茶圣, 影 响后世, 至今其故乡河南济源市的九里沟商有玉川泉、品 茗延寿台、卢全茶社等文化名胜。卢全的《七碗茶歌》还 远播海外。例如, 它在日本广为传颂, 并被演化为“喉吻 润、破孤闷、搜枯肠、发轻汗、肌骨清、通仙灵、清风生”

16 [清]彭定求等编, 《全唐诗》, 郑州: 中原出版传媒集团2018年版, 第388卷, 第1984页。

17 [清]彭定求等编, 《全唐诗》, 郑州: 中原出版传媒集团2018年版, 第522卷, 第2702页。 
的日本茶道。日本人对卢全推崇备至, 经常把他与“茶圣” 陆羽相提并论。

上述三人都是文化人，多以饮茶诗的形式来表达所 遇、所思、所感。他们的茶诗均深受道家、道教的影响, 但因各人的人生经历、思想倾向的不同, 导致他们或以 隐入道, 或以佛融道, 或以儒汇道, 呈现出茶诗的三种 不同韵味。

\section{2. 唐代茶诗道韵的普遍情形}

上述三人并非个例。唐代深受道家、道教影响而创作 了咏茶诗的文化人不算少。例如:

卢纶（739-799年），字允言，今保定波州市卢家场 村人。曾短暂出仕。诗人, 大历十才子之一, 著有《卢户 部诗集》。其《新茶咏寄上西川相公二十三舅大夫二十舅》 说:

三献蓬莱始一尝, 日调金鼎阅芳香。

咜之玉合才半饼, 寄与阿连题数行。1 18

诗中以“蓬莱”比喻仙境, 以炼丹术所用的“调金鼎”代 指烹茶, 暗喻饮茶即炼丹, 饮茶可成仙。

刘言史 (约742--813)，诗人、藏书家，赵州邯郸人。 未仕, 著有歌诗六卷, 《新唐书・艺文志》有传存世。其 《与孟郊洛北野泉上煎茶》说:

粉细越笋芽, 野煎寒溪滨。

恐乘灵草性, 触事皆乎亲。

敲石取鲜火, 僘泉避腥鳞。

苂苂篡风档，拾得坠草薪。

洁色既爽别, 浮氲亦殷勤。

以兹委曲静, 求得正味真。

宛如摘山时, 自歇指下春。

湘瓷泛轻花, 涤尽昏渴神。

此游殹醒趣, 可以话高人。19

此诗强调朴素、纯粹、高洁之茶, 可得真实的“正”味, 能够“涤尽昏渴神”, 成为“高人”。

李群玉（808-862），字文山，唐代澧州人。曾“授弘 文馆校书郎”, 三年后辞官回归故里。著有诗前集3卷, 后 集5卷。《全唐诗》录其诗263首。其诗《琴曲歌辞 升仙 操》说:

嬴女去秦宫, 琼笙飞碧空。凤台闭烟雾, 变吹飘天风。 复闻周太子, 亦遇浮丘公。从簧发天弄, 轻举紫霞中。 浊世不久驻, 清都路何穷。一去霄汉上, 世人那得逢。 ${ }^{20}$ 其茶诗《龙山人惠石文廈方及团茶》描述采茶、著茶、

饮茶, 说:

客有衡岳隐, 遗余石庰茶。自云凌烟露, 采拶春山芽。 汁璧相压叠, 积芳莫能加。碾成黄金粉, 轻嫩如松花。 红炉篡霜枝, 越儿勘井华。滩声起鱼眼, 满鼎漂清霞。 凝澄坐晓月, 病眼如蒙纱。一瓯拂昏䨽, 襟鬲开烦拏。 顾诸与方山, 谁人留品差? 持瓯默吟味, 摇膝空咨磋。 ${ }^{21}$

18 [清]彭定求等编, 《全唐诗》, 郑州: 中原出版传媒集团2018年版, 第2 279 卷, 第 1440 页。

19 [清]彭定求等编, 《全唐诗》, 郑州: 中原出版传媒集团2018年版, 第 468 卷, 第2423页。

20 [清]彭定求等编, 《全唐诗》, 郑州: 中原出版传媒集团2018年版, 第23卷, 第141页。
皮日休 (约838一约883), 字袭美, 一字逸少, 汉 族, 复州竟陵 (今湖北天门) 人。晚唐著名诗人、文学 家。与陆龟蒙齐名, 世称“皮陆”。曾居住在鹿门山, 道 号鹿门子, 又号间气布衣、醉吟先生、醉士等。历任苏 州军事判官 ( 《吴越备史》) 、著作佐郎、太常博士、 毗陵副使。后参加黄巢起事, 或言“陷巢贼中, ${ }^{2}$, 任翰林 学士, 此后不知所终。著有《皮子文薮》 10 卷, 为懿宗 咸通七年皮氏所自编, 收其前期作品。《全唐文》收皮 日休文 4 卷, 其中有散文 7 篇, 为《文薮》所未收。《全 唐诗》收皮日休诗, 共 9 卷 300 余首, 后 8 卷诗均为《文薮》 所未收。皮日休所著咏茶诗主要是: 《杂咏·茶焙》和《茶 中杂咏》中的《茶鼎》 《茶瓯》 《茶人》 《茶舍》 《茶 笋》《茶坞》《茶筑》《茶灶》《煮茶》等, 其《茶笋》 以炼丹比喻烹茶, 说:

衰然二五寸, 生必依岩洞。寒恐结红铅, 暖疑销紫录。

圆如玉轴光, 脆似琼英冻。每为遇之疏, 南山挂幽梦。23

上引四诗的作者卢纶、刘言史、李群玉、皮日休都 是陆羽同时或稍后时期的文人。他们一生中大部分时间 均隐而不仕, 颇有道家风范。他们的诗作颇为关注采摘、 选水、碾磨、用火、调鼎等茶事, 而这些也是炼丹术中 道士烧炼长生不老药的基本步骤。鼎中有霞光异彩是道 士们用来自神其术的话, 受其影响, 李群玉的诗用道士 炼丹用的药物黄金粉来比喻经碾磨后的茶叶。皮日体的 诗则用“红铅”、“紫录”这些道士炼丹中最重要的药物来 比喻茶笋(即茶芽)。这首诗所描述的, 与其说是京茶, 不 如说是炼丹。这显然是道教炼丹术对茶道的影响在唐人 咏茶诗中的体现。

\section{3. 结语}

为什么道家、道教能够对唐代咏茶诗产生这么深刻的 影响呢? 其一, 唐代最高统治者史无前例地把道教位列儒、 佛、道三家之首, 这在文化领域产生了广泛而深远的影响。 文人士大夫阶层对道教趋之若鷔, 理解道家思想, 信仰道 教成为时尚。这必然在茶文化中体现出来。其二, 在文人 士大夫阶层看来, 茶不是喝, 不是饮, 而是要慢慢地品, 在品的过程中, 要收拢散漫放逸之心, 清除偏颇的感情, 淡泊宁静, 返璞归真。于是, 品茶成了展示高雅, 显露素 养、表现自我、通往超越之道的茶道艺术。流风所及, 达 官贵人、文人雅士嗜茶成癖, 乐此不疲: 迎宾待客, 必烹 茶、品茗而清谈; 士人相聚, 必举行茶宴、茶会、茶集, 吟诗联句, 欢乐无穷; 朋友交往, 往往不远千里, 寄赠佳 茗, 共品茶味。

唐代茶诗道韵漫溢, 对后世影响深远。限于篇幅, 另 文阐述。

21 [清]彭定求等编, 《全唐诗》, 郑州: 中原出版传媒集团2018年版, 第568卷, 第2962页。

22 [元]辛文房: 《唐才子传》, 北京: 古典文学出版社1957年版, 第8 卷, 第 143 页。

23 [清]彭定求等编, 《全唐诗》, 郑州: 中原出版传媒集团2018年版, 第611卷, 第3168页。 


\section{致谢}

本文是2019年度教育部人文社会科学研究一般项目 阶段性研究成果, 课题编号: 19YJC760050。

\section{参考文献}

[1] 王巧宏: 《《全唐诗)茶诗文献研究》, 辽宁师范大学硕士 学位论文, 2013年。

[2] 舒曼: 《从古代茶诗看卢全在中国茶文化史上的地位》, 《农业考古》2013年第2期。

[3] 周圣弘、林君妍: 《论卢全的〈饮茶歌〉对宋诗的影响》, 《湖北师范学院学报》( 哲学社会科学版)2012年第5期。

[4] 温孟孚、关剑平: 《道教文化与唐代茶诗》, 《浙江树人 大学学报》，2007年第7期。

[5] 刘学忠: 《道家与古代茶文化》, 《阜阳师范学院学报(社 会科学版)》1997年第1期。
[6] 贾静: 《道教文化与賋然茶诗》, 《中国道教》2011年第8 期。

[7] 赵方任辑注, 《唐宋茶诗辑注》, 北京: 中国致公出版社 2002年版。

[8] 傅璇琮主编, 《唐才子传校笺》第2 册, 北京: 中华书局 1989年版。

[9] [清]彭定求等编, 《全唐诗》, 郑州: 中原出版传媒集团 2018年版。

[10] [唐]赵璘：《因话录・乾巽子》, 北京: 中华书局1985年版。

[11] [唐]陆羽着, 王麓一编, 《茶经》, 北京: 中国纺织出版 社2018年版。

[12] 《新唐书•陆羽传》，北京：中华书局2000年版。

[13] [唐]赵璘, 《钦定四库全书子部1062》, 杭州: 杭州出版 社2015版。

[14] [元]辛文房: 《唐才子传》, 北京: 古典文学出版社 1957 年版。 